nghiên cứu và phát biểu rằng không có mối liên hệ có ý nghĩa giữa mảnh gãy dụng cụ với sự lành thương của các tổn thương quanh chóp. Còn Spili và cs (2005) đã thực hiện nghiên cứu và cho thấy rằng mảnh gãy dụng cụ thực sự ảnh hưởng có ý nghĩa đến sự lành thương của các tổn thương quanh chóp. Chính sự mâu thuẫn này làm cho các bác sĩ lâm sàng cần được cung cấp thông tin dựa trên những bằng chứng rõ ràng hơn để đánh giá được nguy cơ tiềm ẩn của sự cố này [8]. Kế hoạch khắc phục hậu quả khi gãy dụng cụ xảy ra về cơ bản có 2 hướng là quyết định để lại mảnh gãy hay thực hiện lấy mảnh gãy ra. Điều này phụ thuộc vào vị trí của mảnh gãy như chúng tôi đã trình bày bên trên.

\section{KẾT LUÂN}

Khả năng gãy ở hệ thống trâm Protaper quay tay xảy ra khi dụng cụ đã sửa soạn $10 \pm 2.7$ ống tủy. Không có dụng cụ nào bị gãy trong lần sửa soạn đầu tiên. Dụng cụ có suất độ gãy nhiều nhất là trâm S1. Khi sự cố gãy dụng cụ xảy ra, chiều dài mảnh gãy trung bình là $2.13 \pm 1.26 \mathrm{~mm}$. Mảnh gãy thường có xu hướng nằm gần về phía chóp răng hơn là phía miệng ống tủy với khoảng cách trung bình từ đỉnh mảnh gãy tới chóp răng là $3.09 \pm 1.60 \mathrm{~mm}$ và khoảng cách trung bình từ đầu mảnh gãy tới miệng ống tủy là $5.97 \pm 1.84 \mathrm{~mm}$.

\section{TÀI LIÊU THAM KHẢO}

1. Hoàng Tử Hùng (2014), "Bài mở đầu nội nha", Giáo trình giảng day bô môn Chữa răng - Nội nha, Đại học Y Dược thành phố Hồ Chí Minh.
2. Đinh Thi Khánh Vân, "Sửa soạn hệ thống ống tủy (Làm sạch và tạo dạng hệ thống ống tủy)", Giáo trình giảng dạy bộ mốn Nội Nha, Đại học Y Dược TPHCM.

3. Berutti Elio, Chiandussi Giorgio, Paolino Salvatore Davide, Scotti Nicola, Cantatore Giuseppe,Castellucci Arnaldo, and Pasqualini Damiano (2012) "Canal Shaping with WaveOne Primary Reciprocating Files and ProTaper System: A Comparative Study."Journal of Endodontics, 38( HYPERLINK "http://www.sciencedirect.com/science/journal/00 992399/38/4" lo "Go to table of contents for this volume/issue" 4 ), pp.505-509

4. Bùi Quế Dương (2008), "Nội nha lâm sàng", Nhà xuất bản Y học xuất bản lần thứ 2, tr. 91-107, tr. 155-165

5. Wu Jintao, Lei Gang, , Yan Ming,Yu Yan, Yu Jinhua, and Zhang Guangdong (2011) "Instrument Separation Analysis of Multi-used ProTaper Universal Rotary System during Root Canal Therapy."Journal of Endodontics, 37(6), pp.758-763

6. Varela-Patin o Purificacio'n, Iban ̃ezPa'rraga Adalce, Rivas-Mundin a Berta, Cantatore Giuseppe, Otero Luis Xose', and MartinBiedma Benjamin (2010) "Alternating versus Continuous Rotation: A Comparative Study of the Effect on Instrument Life."Journal of Endodontics, 36 (HYPERLINK "http:// www.sciencedirect.com/ science/journal/00992399/36/1" Io "Go to table of contents for this volume/issue" 1 ), pp.157-159

7. Schneider S.W. (1971), "A comparision of canal preparation in straight and curved root canals", Oral Surg Oral Med Oral Pathol, 32(2), pp.271-5.

8. Spili Peter, Parashos Peter, and Messer H. Harold(2005) "The Impact of Instrument Fracture on Outcome of Endodontic Treatment". Journal of Endodontics, 31(12), pp.845-850

\title{
TÌNH TRẠNG SÂU RĂNG VĨNH VIỄN Ở TRẺ EM VIÊTT NAM NĂM 2019
}

\section{TÓM TẮT}

Nghiên cứu nhằm xác định tình trạng sâu răng vĩnh viễn ở trẻ em Việt Nam năm 2019, tữ đó hoạch định các biện pháp dự phòng sâu răng cho trẻ em trong thời gian tới. Nghiên cứu cắt ngang với cỡ mẫu 8053 trẻ em chia làm 4 lứa tuổi $(6-8$ tuổi, $9-11$ tuổi, 12-14 tuổi và 15-17 tuổi) được chọn theo phương pháp ngẫu nhiên, phân tấng nhiều giai đoạn từ 14 tỉnh thành đại diện cho cả nước theo các vùng địa lý. Tình trạng sấu răng ở trẻ em được ghi nhận bởi chỉ số răng sấu - mất - trám (DMFT) và chỉ số mặt

*Bệnh viện Răng Hàm Mặt TU, Hà Nội Chiu trách nhiệm chính: Nguyến Thi Hồng Minh Email: tradentist@gmail.com Ngày nhân bài: 1/3/2021

Ngày phản biên khoa học: 29/3/2021 Ngày duyệt bài: 2/5/2021

\section{Nguyễn Thị Hồng Minh*, Trịnh Đình Hải*}

răng sâu - mất - trám (DMFS) theo tiêu chí của Tồ chức $Y$ tế thế giới kết hợp với chỉ số sâu răng sớm của ICIDAS. Kết quả nghiên cứu cho thấy, sâu răng vĩnh viễn xuất hiện sớm và tăng nhanh theo tuổi. Tỷ lệ sâu răng cao nhất ở nhóm tuối $12-15(43,7 \%)$ và trung bình mối trẻ có một đến hai răng sâu không được hàn, tỷ lệ răng được điêuu trị rất thấp. Kết quả này cho thấy cân đẩy mạnh hơn nữa các biện pháp chăm sóc sức khỏe răng miệng cho trẻ em ở mọi lứa tuổi.

Tư khóa: Sâu răng vĩnh viễn, trẻ em Việt Nam

\section{SUMMARY}

\section{SITUATION OF CARIES IN PERMANENT} DENIIIION IN VIETNAMESE CHILDREN IN 2019

The study aims to identify the situation of caries in permanent dentition in Vietnamese children in 2019, thereby planning measures to prevent dental caries for children in the near future. A cross-sectional study with a sample size of 8053 children divided into age 
groups (6-8; 9-11; $12-14$ and $15-17$ years old) was selected according to the randomized, multi-stage stratification method from 14 provinces representing the whole country by geographic regions. Caries in permanent dentition status was recognized by the tooth decay - loss - fillings index (DMFT) and the surface decay - loss - fillings index (DMFS) according to the World Health Organization criteria combined with the early tooth decay lesion of ICDAS's index. The results showed that permanent caries appeared early and increased rapidly with age. The rate of caries was highest in the age group of $12-15(43.7 \%)$ and on average, each child has 1 to 2 tooth decay without filling, the rate of treated teeth was very low. This result showed that it is necessary to promote dental health care activities for children.

Keywords. Caries in permanent dentition, Vietnamese children

\section{I. ĐăT VẤN ĐỀ}

Bệnh sâu răng là một bênh nhiễm khuẩn phổ biến nhất ở trẻ em, có thể gặp ở mọi lứa tuổi, mọi tầng lớp xã hội. Bệnh xuất hiện sớm và nêu không được phát hiện đièu trị kịp thời sẽ gây ra nhiều biến chứng.Dự phòng sâu răng sớm ở lứa tuổi học đường đã được Tổ chức Y Tế Thế giới (WHO) khuyên cáo cần triển khai. Chương trình chăm sóc răng miệng tại trường học đã và đang được quan tâm và thực hiện ở hầu hết các nước trên thế giới và trong khu vực từ nhiều thập kỷ nay. Tuy nhiên, hiệu quả của những chương trình dự phòng bệnh sâu răng ở các nước trên thế giới không giống nhau. Ở các nước phát triển, sâu răng có xu hướng giảm xuống nhưng lại có xu hướng tăng lên ở các nước đang phát triển. Bệnh sâu răng có diễn biến phức tạp do chịu ảnh hưởng của nhiều yếu tố nguy cớ, như sự hiểu biết, các biện pháp giáo dục của cha me, nhà trường, các phong tục, tập quán và thói quen ăn uống, vệ sinh răng miệng của học sinh. Vì vậy, hiệu quả của các biện pháp dự phòng có thể thay đổi, diễn biến khác nhau theo các vùng, miền khác nhau. Nghiên cứu được tiến hành nhằm đánh giá tình trạng sâu răng ở trẻ em từ đó đưa ra những chiến lược toàn diện chăm sóc sức khoẻ răng miệng cho trẻ em và cộng đồng.

\section{II. Đốl TƯỢNG VÀ PHƯƠNG PHÁP NGHIÊN CỨU \\ 2.1. Đối tượng, địa điểm và thời gian nghiên cứu}

2.1.1. Địa điểm và thời gian nghiên cứu

- Địa điểm: 14 tỉnh thành đại diện cho 7 vùng đia lý của Việt Nam, bao gồm: vùng núi phía bắc, vùng đồng bằng sông Hồng, vùng duyên hải bắc trung bộ, vùng duyên hải nam trung bộ, vùng cao nguyển trung bộ, vùng đông nam bộ và vùng đồng bằng sông Cửu Long.
- Thời gian nghiên cứu: 2016 - 2017.

\subsection{2. Đối tượng nghiên cứu}

+Tiêu chuân lựa chọn: trẻ $6-17$ tuổi, trẻ và bố mẹ đồng ý cho trẻ tham gia nghiên cứu.

+Tiêu chuân loại trừ: trẻ đang mắc các bệnh cấp tính, bố mẹ không đồng ý tham gia nghiên cứu, không hợp tác trong khi nghiên cứu.

\subsection{Phương pháp nghiên cứu}

2.2.1. Thiết kế nghiên cứu: Nghiên cứu mô tả cắt ngang

Trong nghiên cứu này thì các vùng đã chọn mẫu được lựa chọn dựa vào các khu vực địa lý bao phủ cả nước. Việt Nam được phân làm bảy vùng dựa vào vị trí và các đặc điểm địa lý.

Từ 7 vùng này chọn ra 14 tỉnh. Tất cả có 28 quận/huyện được chọn ngẫu nhiên từ 14 tỉnh thành. Ớ mỗi cẩp lựa chon thì xác suất lựa chon cân xứng với số lượng dân số. Trong mỗi quận/huyệ̂n được chọn, lập danh sách tất cả các trường.Mỗi quận/huyện sẽ chọn ngẫu nhiên 03 nhóm trường (mối cụm gồm 1 trường tiểu học, 1 trường THCS, 1 trường THPT). Tổng số có 56 nhóm trường được chọn.

2.2.2. Cỡ mấu và chọn mẫu. Mẫu nghiên cứu chọn theo phương pháp ngấu nhiên, phân tầng nhiều giai đoạn. Mỗi nhóm lại bao gồm 4 nhóm tuổi từ 6 đển 17 tuổi, và các đối tượng nghiên cứu được chọn ngẫu nhiên từ các lớp trong trường tiểu học, trung học cơ sở, và phổ thông trung học.

Nhóm 1 (6-8 tuổi): lớp 1,2,3 (trường tiểu học).

Nhóm 2 (9-11 tuổi): lớp 4,5 (trường tiểu học) và lớp 6 (trường trung học cơ sở).

Nhóm 3 (12-14 tuổi): lớp 7,8,9 (trường trung học cơ sở).

Nhóm 4 (15-17 tuổi): lớp 10,11,12 (trường phổ thông trung học).

Nhóm tuổi được đánh giá tình trạng sâu răng sữa là nhóm 1 và nhóm 2 , trong đó nhóm tuổi then chốt là 6 tuổi. Công thức tính cỡ mẫu cho đơn vị mẫu nhỏ nhất:

$$
n=Z^{2}(1-\alpha / 2) \times \frac{p \times q}{e^{2}}
$$

Trong đó: $\mathrm{n}=$ cõ mẫu nghiên cứu

$$
\begin{aligned}
& Z^{2}{ }_{(1-\alpha / 2)} \text { : hệ số tin cậy, } \mathrm{a}=0,05 \text { thì } \\
& Z^{2}{ }_{(1-\alpha / 2)}=1,96 \\
& \mathrm{P}=\text { tần suất ước tính mắc bệnh sâu răng ở }
\end{aligned}
$$
trẻ em, $p=0,8(80 \%)$.

$q=1-p=0,2$

e = độ chính xác tuyệt đối mong muốn (confident limit around the point estimate), thường lấy $=0.05(5 \%)$. 
Từ công thức tính được $\mathrm{n}=122$. Ước lượng sai số $5 \%$ ta có cỡ mẫu là 128 .

Như vây, cõ̃ mẫu cho mỗi trường là 128 đối tượng. Mỗi nhóm tuổi sẽ có 32 đối tượng.

Cỗ mẫu của điều tra ở trẻ em là: 7168 đôii tương.

Thực tế nghiên cứu đã khám cho 8043 trẻ em, đảm bảo lớn hơn cỡ mẫu đã tính.

\subsubsection{Các bước tiến hành}

\subsubsection{Chuẩn bị nghiên cứu}

* Liên hệ cơ sở thực hiện nghiên cứu:

- Liên hể với Ủy ban Nhân dân và cơ quan y tế của các tỉnh/ thành, huyện/ quận và xã/ phường đã được chọn và đề nghị cử cán bộ phối hợp nghiên cứu.

- Lập danh sách học sinh và chọn ngẫu nhiên theo cỡ mẫu.

- Gửi phiếu xác nhận đồng ý tham gia nghiên cứu của phụ huynh trẻ và phiếu câu hỏi

* Tập huấn cho cán bộ nghiên cứu

Chỉ sử dụng những người khám đã được tập huấn và định chuẩn. Viêc tâp huấn và định chuẩn đã được tiến hành ở Hà Nội và thành phố Hồ Chí Minh.

* Chuẩn bị dụng cụ, công cụ khám răng

- Chuẩn bị dụng cụ: bộ khay khám răng(khay quả đậu, gương, thám châm, cây thăm dò nha chu, gắp), bông, cốc nhựa.

- Nguồn sáng: đèn sợi quang học có kèm theo gương khám

- Phiếu khám: theo mẫu của Tổ chức $Y$ tế thế giới "Điều tra sức khỏe răng miệng - Các phương pháp cơ bản", xuất bản lần thứ 5, năm 2013.

- Áp dụng các biện pháp vô khuẩn theo đúng qui trình

2.2.3.2. Quy trình thực hiện khám lâm sàng

\section{KẾT QUẢ NGHIÊN CỨU}

\section{Bảng 1. Tình trạng sâu răng vĩnh viễn}

- Khám bằng dụng cụ chuyên khoa dưới ánh sáng đèn sợi quang học

- Người khám là các Bác sĩ Răng Hàm Mặt của Bệnh viện Răng Hàm Mặt Trung ương Hà Nôi và Thành phố Hồ Chí Minh đã được tâp huấn định chuẩn đánh giá lâm sàng và ghi nhận các tình trạng sâu răng.

- Trẻ em được khám tư thễ nằm trên bàn thấp.

- Cách khám: khám theo cùng môt cách thức cho mỗi trẻ em, theo thứ tự bắt đầu từ

răng 55 cho đến răng 65 ở hàm trên, tiếp đến từ răng 75 đến răng 85 ở hàm dưới để tránh bỏ sót. Khám toàn bộ các mặt răng rồi đọc mã số cho người ghi chép vào phiếu khám.

- Ghi nhận tình trạng sâu răng vĩnh viễn:

\begin{tabular}{|c|l|}
\hline 0 & Răng bình thường \\
\hline D1 & Tổn thương sớm trên men răng \\
\hline D2 & $\begin{array}{l}\text { Tổn thương trên men, có mất cấu trúc } \\
\text { men }\end{array}$ \\
\hline D3 & $\begin{array}{l}\text { Tốn thương mất khoáng, tạo bóng đổi } \\
\text { màu ở ngà răng, chưa hìn thành lố } \\
\text { sâu ở ngà }\end{array}$ \\
\hline 1 & Răng sâu \\
\hline 2 & Răng hàn bị sâu \\
\hline 3 & Răng hàn không bị sâu \\
\hline 4 & Răng mất do sâu \\
\hline 5 & Răng mất không do sâu \\
\hline 6 & Răng trám bít hố rãnh \\
\hline 7 & Răng giả cố định, chụp răng, mặt dán \\
\hline 8 & Răng chưa mọc \\
\hline 2 & $4 . x u ̛$ lýn \\
\hline
\end{tabular}

2.2.4. Xử lý và phân tích số liệu

- Các phiếu khám được kiểm tra trong ngày, điều chỉnh các sai sót (nếu có) ngay cuối buổi khám.

- Các số liệu được phân tích và xử lý bằng phần mềm thống kê y học SPSS 16.0.

\begin{tabular}{|c|c|c|c|c|c|c|c|c|c|c|}
\hline \multirow{2}{*}{ tuổi } & \multirow{2}{*}{$\mathbf{n}$} & \% & \multicolumn{9}{|c|}{ DMFT } & \multicolumn{4}{c|}{ DMFS } \\
\cline { 4 - 11 } & & & DT & MT & FT & DMFT & DS & MS & FS & DMFS \\
\hline $6-8$ & 420 & 20,9 & 0,43 & 0,01 & 0,04 & 0,48 & 1,21 & 0,01 & 0,06 & 1,28 \\
\hline $9-11$ & 692 & 34,4 & 0,80 & 0,02 & 0,11 & 0,93 & 2,78 & 0,02 & 0,18 & 2,98 \\
\hline $12-14$ & 879 & 43,7 & 1,37 & 0,04 & 0,21 & 1,62 & 4,70 & 0,04 & 0,30 & 5,03 \\
\hline $15-17$ & 731 & 36,3 & 1,17 & 0,07 & 0,30 & 1,54 & 4,33 & 0,07 & 0,40 & 4,81 \\
\hline
\end{tabular}

Nhận xét: Sâu răng vĩnh viễn xuất hiện sớm và tăng nhanh theo tuối, Từ $6-8$ tuối đã có $20,9 \%$ số trẻ có sâu răng vĩnh viễn,số răng vĩnh viễn sâu tăng lên theo tuổi. trung bình mối trẻ có 1 đến 2 răng sâu. Mức đô sâu răng cũng tăng dần theo tuổi và tỷ lê răng được điêuu trị rất thấp.

Bảng 2:Tình trạng sâu răng vĩnh viến theo tuôii và giới

\begin{tabular}{|c|c|c|c|c|c|c|c|}
\hline \multirow{2}{*}{ Tuổi } & \multirow{2}{*}{ Giới } & \multirow{2}{*}{$\mathbf{n}$} & \multirow{2}{*}{ Tỷ lệ } & \multicolumn{4}{|c|}{ DMFT } \\
\hline & & & & DT & MT & FT & DMFT \\
\hline \multirow{2}{*}{$6-8$} & nam & 239 & 20,5 & 0,43 & 0,01 & 0,04 & 0,48 \\
\hline & nữ & 181 & 21,4 & 0,42 & 0,01 & 0,05 & 0,47 \\
\hline \multirow{2}{*}{$9-11$} & nam & 383 & 34,3 & 0,82 & 0,01 & 0,11 & 0,93 \\
\hline & nữ & 309 & 34,4 & 0,78 & 0,02 & 0,11 & 0,92 \\
\hline
\end{tabular}


TẠP CHÍ Y HỌC VIỆT NAM TẬP 502 - THÁNG 5 - SỐ 1 - 2021

\begin{tabular}{|c|c|c|c|c|c|c|c|}
\multirow{2}{*}{$12-14$} & nam & 477 & 45,5 & 1,49 & 0,04 & 0,17 & 1,69 \\
\cline { 2 - 7 } & nữ & 402 & 41,8 & 1,30 & 0,04 & 0,25 & 1,59 \\
\hline \multirow{2}{*}{$\mathbf{1 5 - 1 7}$} & nam & 344 & 33,3 & 1,10 & 0,05 & 0,27 & 1,42 \\
\cline { 2 - 7 } & nữ & 387 & 39,4 & 1,31 & 0,09 & 0,34 & 1,74 \\
\hline
\end{tabular}

Nhận xét: Tỷ lệ sâu răng tăngtheo thời gian ở cả hai giới. Ớ lứa tuối từ 6 đến 11 , sâu răng cả hai giới không có sự khác biệt, tuy nhiên khi trẻ lớn hơn thisâu răng của nam và nữ có sự khác nhau, ở nhóm 12 - 14 tuổi sâu răng của nam lớn hơn nữ, trong khi đó ở nhóm 15 -17 tuổi lại cho kết quả nữ cao hơn nam.

Bảng 3.Tình trang sâu răng ở các nhóm tuổi then chốt theo giới

\begin{tabular}{|c|c|c|c|c|c|c|c|}
\hline Tuối & Giới & $n$ & $\%$ & DT & MT & FT & DMFT \\
\hline \multirow{2}{*}{12} & Nam & 163 & 46,6 & 1,38 & 0,03 & 0,15 & 1,56 \\
\hline & nữ & 136 & 42,9 & 1,20 & 0,05 & 0,30 & 1,56 \\
\hline \multirow{2}{*}{15} & Nam & 106 & 30,6 & 0,90 & 0,05 & 0,36 & 1,31 \\
\hline & nữ & 129 & 40,1 & 1,44 & 0,08 & 0,43 & 1,95 \\
\hline
\end{tabular}

Nhân xét: Ỡ lứa tuối 12 , tình trạng sâu răng ở nam cao hơn nữ, tuy nhiên chỉ số DMFT lại gần bằng nhau. Ở trẻ 15 tuổi, hoc sinh nữ sâu răng nhiều hơn nam rõ rệt, chỉ số DMFT cũng cao hơn nhiêu.

Bảng 4. Tình trạng sâu răng vĩnh viễn theo các vùng địa lý.

\begin{tabular}{|c|c|c|c|c|c|c|c|}
\hline & & & & & & & \\
\hline Vung & tuol & $\mathrm{n}$ & $\%$ & DT & MT & FT & DMFT \\
\hline & $6-8$ & 50 & 17,4 & 0,35 & 0,04 & 0,05 & 0,44 \\
\hline & $9-11$ & 75 & 26,0 & 0,56 & 0,02 & 0,12 & 0,70 \\
\hline Vùng núi phía bắc & $12-14$ & 81 & 28,1 & 0,70 & 0,02 & 0,25 & 0,97 \\
\hline & $15-17$ & 74 & 25,7 & 0,62 & 0,08 & 0,45 & 1,15 \\
\hline & Chung & 280 & 24,3 & 0,54 & 0,04 & 0,19 & 0,77 \\
\hline & $6-8$ & 64 & 22,2 & 0,48 & 0,00 & 0,15 & 0,63 \\
\hline & $9-11$ & 116 & 40,3 & 1,30 & 0,00 & 0,16 & 1,46 \\
\hline Vùng ĐBSH & $12-14$ & 156 & 54,2 & 1,81 & 0,00 & 0,40 & 2,21 \\
\hline & $15-17$ & 109 & 37,8 & 1,31 & 0,02 & 0,28 & 1,61 \\
\hline & Chung & 445 & 38,6 & 1,19 & 0,00 & 0,24 & 1,43 \\
\hline & $6-8$ & 35 & 12,2 & 0,25 & 0,01 & 0,04 & 0,30 \\
\hline & $9-11$ & 93 & 32,3 & 0,79 & 0,02 & 0,28 & 1,09 \\
\hline Vùng duyên hải BTB & $12-14$ & 125 & 43,4 & 1,54 & 0,05 & 0,30 & 1,89 \\
\hline & $15-17$ & 88 & 30,6 & 0,93 & 0,03 & 0,41 & 1,37 \\
\hline & Chung & 341 & 29,6 & 0,84 & 0,03 & 0,24 & 1,11 \\
\hline & $6-8$ & 42 & 14,6 & 0,26 & 0,00 & 0,06 & 0,32 \\
\hline & $9-11$ & 67 & 23,3 & 0,35 & 0,02 & 0,15 & 0,52 \\
\hline Vùng duyên hải NTB & $12-14$ & 60 & 20,8 & 0,37 & 0,03 & 0,30 & 0,70 \\
\hline & $15-17$ & 60 & 20,8 & 0,50 & 0,06 & 0,35 & 0,91 \\
\hline & Chung & 229 & 19,9 & 0,37 & 0,03 & 0,22 & 0,62 \\
\hline & $6-8$ & 46 & 16,0 & 0,29 & 0,00 & 0,06 & 0,35 \\
\hline & $9-11$ & 103 & 35,8 & 0,78 & 0,01 & 0,23 & 1,02 \\
\hline Vùng cao nguyên TB & $12-14$ & 155 & 54,0 & 1,83 & 0,04 & 0,42 & 2,29 \\
\hline & $15-17$ & 140 & 48,6 & 1,45 & 0,12 & 0,74 & 2,31 \\
\hline & Chung & 444 & 38,6 & 1,07 & 0,04 & 0,36 & 1,47 \\
\hline & 6-8 & 111 & 38,5 & 0,45 & 0,01 & 0,02 & 0,48 \\
\hline & $9-11$ & 138 & 47,9 & 1,32 & 0,00 & 0,10 & 1,42 \\
\hline Vùng ĐNB & $12-14$ & 169 & 58,9 & 2,23 & 0,04 & 0,25 & 2,52 \\
\hline & $15-17$ & 144 & 50,0 & 2,21 & 0,06 & 0,38 & 2,65 \\
\hline & Chung & 562 & 48,8 & 1,56 & 0,03 & 0,19 & 1,78 \\
\hline & $6-8$ & 72 & 25,2 & 0,42 & 0,00 & 0,01 & 0,43 \\
\hline & $9-11$ & 100 & 35,0 & 0,85 & 0,02 & 0,04 & 0,91 \\
\hline Vùng ĐB SCL & $12-14$ & 133 & 46,7 & 1,38 & 0,09 & 0,16 & 1,63 \\
\hline & $15-17$ & 116 & 40,6 & 1,58 & 0,15 & 0,28 & 2,01 \\
\hline & Chung & 421 & 36,8 & 1,07 & 0,07 & 0,13 & 1,27 \\
\hline
\end{tabular}


Nhận xét: Mỗi vùng địa lý có sự phân bố tỷ lệ sâu răng khác nhau. Vùng đồng bằng sông Hồng, vùng cao nguyên trung bộ, vùng đông nam bộ, vùng đồng bằng sông Cửu Long cho thấy tỷ lệ sâu răng vĩnh viền cao hơn và tăng lên theo tuổi của trẻ. Vùng miên núi phía bắc, duyên hải bắc trung bộ, duyên hải nam trung bộ có tỷ lệ sâu răng vĩnh viễn thấp hơn.

\section{BÀN LUÂN}

Tình trạng sâu răng vĩnh viễn ở trẻ em được ghi nhận bởi chỉ số răng sâu - mất - trám (DMFT) và chỉ số mặt răng sâu - mất - trám (DMFS). Chỉ số DMFT là số trung bình răng sâu (DT), răng sâu đã mất (MT) và răng sâu đã trám (FT). Chỉ số DMFS là số trung bình mặt răng sâu (DS), mặt răng đã mất do sâu (MS) và mặt răng sâu đã trám (FS).

Theo kết quả nghiên cứu ở bảng 1, tỷ lệ sâu răng vĩnh viễn là một vấn đề cần phải quan tâm, sâu răng vĩnh viễn xuất hiện với tỷ lệ cao khi vừa mới mọc (nhóm $6-8$ tuổi) và tăng dần theo tuổi, từ' tuổi tỷ lệ sâu răng vĩnh viễn của trẻ đã rất nghiêm trọng( $34,4 \%-43,7 \%)$, tỷ lệ răng được điều trị thấp, tuy nhiên so với răng sữa thì tỷ lệ DMFT và DMFS thấp hơn rất nhiêu, điều này có thể lý giải về cấu trúc giải phẫu - mô học của răng vĩnh viễn bền vững hơn so với răng sữa. Mặc dù vậy, trẻ lại bị sâu răng vĩnh viễn từ rất sớm ngay khi vừa mới mọc lên, do đó đòi hỏi tăng cường giáo dục vệ sinh răng miệng cho cộng đồng cũng như sự quan tâm chăm sóc sức khỏe răng miệng của chính bản thân đứa trẻ cũng như từ các bậc phụ huynh.

Ớ bảng 2, tỷ lể sâu răng tăng theo thời gian ở cả hai giới, ở lứa tuổi từ 6 đến 11, tỷ lệ sâu răng cả hai giới không có sự khác biệt, tuy nhiên khi trẻ lớn hơn thì tỷ lệ sâu răng của nam và nữ đã có sự khác nhau, Một số nghiên cứu cho rằng các bạn nữ thường có ý thức về chăm sóc bản thân hơon các bạn nam, vì vậy vấn đề răng miệng cũng được cải thiện hơn.

Lý do dẫn đến tình trạng sâu răng cao ở trẻ có thế được giải thích bởi nhiều yếu tố khách quan cũng như chủ quan, như thói quen ăn uống nhiều bữa của trẻ, ăn nhiều thức ăn có chứa đường như sữa, bánh kẹo, nước ngọt..., vệ sinh răng miệng kém, chưa có các biện pháp dự phòng sâu răng hợp lý, nồng độ fluor trong nguồn nước sinh hoạt không đủ...Bên cạnh đó ở lứa tuổi này trẻ đang ở trong giai đoạn hàm răng hỗn hợp, những thay đổi về giải phẫu của răng và lợi cũng làm khó dễ cho vấn đề vệ sinh răng miệng và sự tích tụ theo thời gian của một quá trình sâu răng từ khi trẻ còn nhỏ...

Kết quả bảng 4, tỷ lệ sâu răng vĩnh viễn ở trẻ em đều cao, trung bình mỗi trẻ có 1 răng bị sâu hoặc mất do sâu hoăcc đã hàn. Mỗi vùng địa lý đều cho thấy tỷ lệ sâu răng vĩnh viễn tăng lên theo tuổi của trẻ, trong các vùng địa lý cho thấy vùng miền núi phía bắc và duyên hải nam trung bộ có tỷ lệ sâu răng vĩnh viễn thấp hơn so với các vùng khác, cần phải có nghiên cứu sâu hơn để lý giải vấn đề này. Điềunày có thể lý giải bởi điều kiện phát triển kinh tế xã hội ở vùng này cao hơn các vùng khác, công tác nha học đường được chú trọng và quan trọng nhất ở vùng này được fluor hóa nguồn nước cấp công cộng. Số răng sữa bị sâu trên mỗi trẻ ở các vùng miền đều cao, trung bình mỗi trẻ có khoảng 6 răng sữa sâu, gây ảnh hưởng lớn đến sự phát triển thể chất của trẻ. Điều này nhắc nhở chúng ta cần quan tâm hơn nữa đến vấn đề nguy cơ sâu răng của trẻ, đòi hỏi nhiều đến công tác dự phòng tại cộng đồng, bao gồm công tác giáo dục nâng cao nhận thức về chăm sóc sức khỏe răng miệng tại cộng đồng, cũng như sự quan tâm của bộ máy chính quyền của nhà nước vào các chương trình bảo vệ sức khỏe răng miệng như fluor hóa nước cấp công cộng, fluor hóa muối ăn, các chính sách nhà nước để hạn chế người dân sử dụng đường...

\section{KẾT LUẬN}

- Có $86,4 \%$ trẻ em từ $6-8$ tuổi bị sâu răng sữa và chỉ số dmft trung bình là 6,21 , trong đó mỗi em có trung bình 5 răng sâu không được điều trị.

- Có khoảng $1 / 4$ số trẻ em 6 tuổi có từ một đến sáu răng sâu.

Tỷ lệ sâu răng sữa cao ở tất cả các vùng địa lý (trừ vùng Đông Nam bộ).

\section{TÀl LIỆU THAM KHẢO}

1. Gugnani. N. International Caries Detection and Assessment System (ICIDAS): A newConcept. Int J Clin Pediatr Dent 2011 May-Aug; 4(2): 93-100.

2. Thống kê y học 1996. Nhà xuất bản Hanoi , 1997

3. Trịnh Đình Hải, Đào Ngọc Phong. Phương pháp nghiên cứu dịch tễ học lâm sàng trong Nha khoa. Nhà xuất bản Y học, Hà Nội, 2014.

4. Trường.TV; Hải. TĐ. Điêuu tra sức khỏe răng miệng toàn quốc. Nhà xuất bản Y học, 2002.

5. Trương Mạnh Dũng, Vũ Mạnh Tuấn (2011) "Thực trạng bệnh răng miệng và một số yếu tố liên quan ở trẻ 4-8 tuổi tại 5 tỉnh thành của Việt Nam năm 2010", Y Học Thực Hành, 797 (12), tr56-59.

6. World Health Organization. Oral health Survey - Basic methods, 5th Edition. Geneva, WHO, 2013 